\section{CRITICAL MEDICAL AND SURGICAL NURSING JOURNAL \\ Vol. 10, No. 1, April 2021}

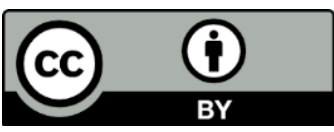

This is an Open Access article distributed under the terms of the Creative Commons Attribution 4.0 International License

\title{
Relationship of Hypertension Control Factors with Blood Pressure in Hypertension Patients at Pandanwangi Primary Health Care Malang
}

\author{
Devi Rahmaningrum Wardani1, Erna Dwi Wahyuni2 ${ }^{\circledR}$, Lailatun Ni'mah $^{2}$ (D) \\ 1 Bachelor Student, Faculty of Nursing, Universitas Airlangga, Surabaya, Indonesia \\ ${ }^{2}$ Faculty of Nursing, Universitas Airlangga, Surabaya, Indonesia
}

\section{ARTICLE HISTORY \\ Received: Feb 8, 2021 \\ Accepted: March 15, 2021 \\ Published: IN PRESS}

\section{KEYWORDS}

control, blood pressure, hypertension

CORRESPONDING AUTHOR

Erna Dwi Wahyuni erna-dw@fkp.unair.ac.id

Faculty of Nursing, Universitas Airlangga,

Surabaya, Indonesia

\begin{abstract}
Introduction: Hypertension is a common cause of the increase of mortality rate and morbidiety in the community. Complications of hypertension cause approximately 9.4 deaths around the world each year. The purpose of this study is to analyze the relationship of factors controlling hypertension with blood pressure.

Methods: This study used a descriptive correlational design with the cross sectional approach. The study population was patients with hypertension in Puskesmas Pandanwang Malang City. The sample used as many as 96 people based on purposive sampling technique. The instruments used were questionnaire sheets, spyghmomanometer and stethoscope. Analysis using the test Spearman rho test with a significance level of $p<0.005$.

Result: The results showed there are a relationship between knowledge ( $p=0.000$ and $r=$ $0.778)$, attitude $(p=0.000$ and $r=0.626)$, diet $(p=0.000$ and $r=0.609)$, physical activity $(p$ $=0.000$ and $r=0.449)$, family support $(p=0.000$ and $r=0.607)$, and medication adherence $(\mathrm{p}=0.000$ and $\mathrm{r}=0.726)$ with blood pressure .

Conclusion: There is a significant relationship and the direction between the knowledge, attitude, diet, physical activity, family support, and medication adherence with blood pressure.
\end{abstract}

Wardani, D. R., Wahyuni, E. D., \& Ni'mah, L. (2021). Relationship of Hypertension Control Factors with Blood Pressure in Hypertension Patients at Pandanwangi Primary Health Care Malang. Crit. Méd. Surgical. Nurs. J, 10(1), xx-xx.

\section{INTRODUCTION}

Patients Attention to Non-Communicable Diseases (PTM) is currently increasing along with the increasing frequency of PTM occurrences in the community. Hypertension is one of the noncommunicable diseases that has increased the incidence in society. The increase in the incidence of hypertension is related to a lifestyle, including smoking, alcohol consumption, physical activity and less consumption of fruits and vegetables. Hypertension is also called the silent killer because it is one of the causes of increased morbidity and mortality. This shows how important hypertension is to be overcome, one way is to control blood pressure to keep it in a normal state. Blood pressure control must be done so that there is no increase in the incidence of hypertension.(Maharani \& Syafrandi, 2017). However, until now the relationship between these factors and blood pressure has not been explained.

World Health Organization (WHO) states that hypertension contributes to nearly 9.4 million deaths from cardiovascular disease every year (WHO, 2013). WHO data for 2015 shows that around 1.13 billion people in the world have hypertension. The number 
of people with hypertension continues to increase every year, it is estimated that by 2025 there will be 1.5 billion people affected by hypertension, and it is estimated that each year 9.4 million people die from hypertension and its complications. Rikesdas (2018) data shows the prevalence of hypertension in Indonesia reaches 34.1\%. Data from Riskesdas of East Java Province, prevalence of hypertension reached 26.2\%. Data from the Malang City Health Office in 2018, in the target area of Pandanwangi Health Center, Malang City, there were 31,799 people aged over 15 years, 25,426 people who had blood pressure measurements taken, and there are 2,677 people who suffer from hypertension (10.53\%). And in 2019 hypertension sufferers at Pandanwangi Health Center increased to 2,766 people.

Data Sample Registration System (SRS) Indonesia in 2014, hypertension with complications $(5.3 \%)$ is the number five cause of death at all ages. Meanwhile, based on International Health Metrics Monitoring and Evaluation (IHME) data in 2017 in Indonesia, the cause of death in the first rank is caused by stroke, followed by ischemic heart disease which is a complication of hypertension (Ministry of Health, 2019).About $40 \%$ of deaths at a young age are due to uncontrolled hypertension (Artiyaningrum, 2016). Data from the AHA (American Heart Association) in 2011, in America, from 59\% of people with hypertension, only $34 \%$ whose blood pressure is controlled(Artiyaningrum, 2016).

An increase in blood pressure that lasts for a long time (persistent) can lead to complications or damage to the body's organ systems, such as the kidneys (kidney failure), heart (coronary heart disease), and brain (stroke) if not detected early and get proper treatment. adequate. Hypertension triggers the atherosclerotic plaque in the cerebral arteries and arterioles, which can cause arterial occlusion, ischemic injury and stroke as long-term complications (Yonata, 2016). Hypertension complications cause approximately 9.4 deaths worldwide each year. Hypertension causes at least $45 \%$ of deaths due to heart disease and $51 \%$ of deaths due to stroke. Deaths caused by cardiovascular disease, especially coronary heart disease and stroke are estimated to continue to increase to 23,(Datin, 2014).

Hypertension sufferers must be able to control their blood pressure in order to remain stable under normal conditions, this is aimed at avoiding complications and DRPs. According to JNC 8, the target stable blood pressure at $<60$ years of age is $<140 / 90 \mathrm{mmHg}$, and at $>60$ years of age it is $<150 / 90$ mmHg. Controlling blood pressure can be started by increasing the knowledge of patients and families about hypertension and its control, increasing attitudes and physical activity, adhering to diet and adhering to taking medication. Efforts to control blood pressure are not only the responsibility of sufferers, but family and health workers also play an important role in efforts to control blood pressure(Maharani \& Syafrandi, 2017).

This study was conducted to prove the theory of Lawrence W. Green with the Precede-Proceed Model on health behavior in hypertensive patients in controlling their blood pressure. The aim is to analyze the relationship between hypertension control factors and blood pressure in hypertensive patients, which are grouped into three, namely predisposing factors, supporting factors, and driving factors (Nursalam, 2016).

\section{METHOD}

This study used a non-experimental research design with a descriptive correlational design through a cross sectional approach which aims to explain and identify factors associated with hypertension control in hypertensive patients who are in the Pandanwangi Community Health Center, Malang City. The population of this study were all hypertension 
sufferers at Pandanwangi Public Health Center Malang City in February 2020, amounting to 172 patients. The sample size of this study was 96 respondents who were selected by using purposive sampling technique. The inclusion criteria in this study were hypertensive patients aged 40-65 years, able to communicate well, currently undergoing antihypertensive drug therapy, and living with family. The exclusion criteria in this study were hypertensive patients with complications, such as stroke, coronary heart disease, etc. and hypertensive patients who were pregnant. This research was conducted at Pandanwangi Health Center, Malang City.

Data collection was carried out from June to July 2020. The variables in this study were divided into two, namely independent and dependent. The independent variables in this study were knowledge, attitude, physical activity, diet, family support, and medication adherence. The dependent variable studied was blood pressure in hypertensive patients at Pandanwangi Health Center, Malang City.The instruments used in this study were a questionnaire sheet, spyghmomanometer, and stetochop.

There are 7 questionnaires, including the questionnaire on demographics, knowledge, attitudes, diet, physical activity, family support, and medication adherence. The demographic questionnaire consisted of 5 questions, namely age, gender, latest education, smoking habits, and types of drugs consumed. The questionnaire for knowledge, attitudes, and diet is a modification of the previous research conducted by Riri in 2017 and the researcher has tested the validity of the reliability. The physical activity questionnaire was adopted from research conducted previously by Denny Purwawardana in 2018. The questionnaire for medication adherence used the Morisky drug adherence questionnaire (MMAS) and had been tested for reliability validity by Mulyasari in 2016. The family support questionnaire used was sourced from Nursalam in 2017. Data analysis was performed
Table 1 Distribution of Demographic Characteristics of Respondents at Pandanwangi Health Center, Malang City

\begin{tabular}{llcc}
\hline \multicolumn{1}{c}{ Parameter } & n & \% \\
\hline Age & Early elderly & 42 & 43.8 \\
& Late elderly & 47 & 49 \\
& Seniors & 7 & 7.3 \\
& Total & 96 & 100 \\
\hline Gender & Women & 57 & 59.4 \\
& Man & 39 & 40.6 \\
& Total & 96 & 100 \\
\hline Education & SD & 15 & 15.6 \\
& Junior High & 16 & 16.7 \\
& High school & 44 & 45.8 \\
& College & 21 & 21.9 \\
& Total & 96 & 100 \\
\hline Smoke & Yes & 30 & 31.2 \\
& Not & 66 & 68.8 \\
& Total & 96 & 100 \\
\hline Type of & Nifedipine & 7 & 7.3 \\
Medicine & Amlodipine & 71 & 74 \\
& Captropil & 18 & 18.8 \\
& Total & 96 & 100 \\
\hline
\end{tabular}

using a computerized system in 2 ways, namely univariate analysis and bivariate analysis. Univariate analysis is used to calculate the frequency and proportion to determine the characteristics and variables to be studied.

Bivariate analysis was used to determine the relationship between the 6 independent variables and the dependent variable one by one using spearmen correlation analysis. The software used is SPSS version 21. Univariate analysis is used to calculate the frequency and proportion to determine the characteristics and variables to be studied. Bivariate analysis was used to determine the relationship between the 6 independent variables and the dependent variable one by one using spearmen correlation analysis. The software used is SPSS version 21. Univariate analysis is used to calculate the frequency and proportion to determine the characteristics and variables to be studied. Bivariate analysis was used to determine the relationship between the 6 independent variables and the dependent variable one by one using spearmen correlation analysis. The software used is SPSS version 21. This research procedure has been reviewed and approved by Ethics Commission for 
Table 2 Distribution of respondents based on research variables at Pandanwangi Health Center, Malang City

\begin{tabular}{cccc}
\hline Variable & Category & n & \% \\
\hline Knowledge & Less & 35 & 36.5 \\
& Enough & 33 & 34.4 \\
& Good & 28 & 29.2 \\
& Total & 96 & 100 \\
\hline Attitude & Negative & 49 & 51 \\
& Positive & 47 & 49 \\
& Total & 96 & 100 \\
\hline Diet & Negative & 51 & 53.1 \\
& Positive & 45 & 46.9 \\
& Total & 96 & 100 \\
\hline Physical & Negative & 64 & 66.7 \\
Activity & Positive & 32 & 33.3 \\
& Total & 96 & 100 \\
\hline Family & Less & 46 & 47.9 \\
support & Enough & 39 & 40.6 \\
& Good & 11 & 11.5 \\
& Total & 96 & 100 \\
\hline Compliance & Low & 52 & 54.2 \\
with & Moderate & 21 & 21.9 \\
Medication & High & 23 & 24 \\
& Total & 96 & 100 \\
\hline Blood & Not On Target & 67 & 69.8 \\
pressure & On target & 29 & 30.2 \\
& Total & 96 & 100 \\
\hline & & & \\
& &
\end{tabular}

Health Research, Faculty of Nursing, Airlangga University with No. 2044-KEPK.

\section{RESULT}

Table 1 shows that the characteristics of the majority of respondents are in the late elderly group, namely as many as 47 respondents (49\%), most of the respondents, namely 57 respondents (59.4\%) are female, in terms of education, the latter is dominated by SMA level, namely as many as 44 respondents (45.8\%), the majority of respondents did not have a smoking habit as many as 66 (68.8\%), and most of the drugs consumed by the respondents were amlodipine, as many as 71 respondents (74\%).

Table 2 shows that the majority of respondents, namely 35 respondents (36.5\%) have less knowledge, the majority of respondents have a negative attitude, namely as many as 49 respondents (51\%), the majority of negative diets, namely as many as 51 respondents (53.1\%), the majority of physical activity negative, namely as many as 64 respondents (66.7\%), the majority of respondents had less family support, namely 46 respondents (47.9\%), compliance with taking medication, the majority of respondents were low, namely 52 respondents (54.2\%), and for blood pressure. the majority did not meet the target, as many as 67 respondents (69.8\%).

Table 3 shows that the majority of respondents have less knowledge about blood pressure that is not on target as many as 35 respondents (36.5\%). Based on the results of the analysis using the Spearman Rank Test Correlation statistical test, it was found that the value of $p=0.000$ and $r=0.778$. A value $<0.05$ means that $\mathrm{H} 1$ is accepted and indicates a relationship between knowledge and blood pressure. The correlation coefficient is positive $(r=0.778)$, which means that the strength of the relationship between knowledge and blood pressure is strong and unidirectional. The existence of a strong and unidirectional relationship shows that the better the level of knowledge, the better the blood pressure in hypertensive patients at Pandanwangi Health Center, Malang City.

Table 4 shows that the majority of respondents have a negative attitude with blood pressure not on target as many as 48 respondents (50\%). Based on the results of the analysis using the Spearman Rank Test Correlation statistical test, it was found that the value of $p=0.000$ and $r=0.626$. $P$ value $<0.05(p=$ 0.000) means $\mathrm{H} 1$ is accepted and indicates a relationship between attitude and blood pressure in hypertensive patients at Pandanwangi Health Center, Malang City. The value of the correlation coefficient is positive $(r=0.626)$, which means that the strength of the relationship between attitude and blood pressure is strong and unidirectional. The existence of a strong and unidirectional relationship shows that the better the attitude, the more controlled blood pressure is in 


\section{R. WARDANI ET AL.}

Table 3: Cross Tabulation Of The Relationship Between Knowledge And Blood Pressure In Hypertensive Patients At Pandanwangi Health Center, Malang City

\begin{tabular}{|c|c|c|c|c|c|c|}
\hline \multirow{3}{*}{ Knowledge } & \multicolumn{4}{|c|}{ Blood pressure } & \multirow{2}{*}{\multicolumn{2}{|c|}{ Total }} \\
\hline & \multicolumn{2}{|c|}{ Not on target } & \multicolumn{2}{|c|}{ On target } & & \\
\hline & $\mathrm{n}$ & $\%$ & $\mathrm{n}$ & $\%$ & $\mathrm{n}$ & $\%$ \\
\hline Less & 35 & 36.5 & 0 & 0 & 35 & 36.5 \\
\hline Enough & 30 & 31.3 & 3 & 3,1 & 33 & 34.4 \\
\hline Good & 2 & 2.1 & 26 & 27.2 & 28 & 29.2 \\
\hline Total & 67 & 69.8 & 29 & 30.2 & 96 & 100 \\
\hline
\end{tabular}

Spearman Rho Test Statistical Test $\mathrm{p}=0.000$ and $\mathrm{r}=0.778$

Table 4 Cross Tabulation Of The Relationship Between Attitude And Blood Pressure In Hypertensive Patients At Pandanwangi Health Center, Malang City

\begin{tabular}{|c|c|c|c|c|c|c|}
\hline \multirow{3}{*}{ Attitude } & \multicolumn{4}{|c|}{ Blood pressure } & \multirow{2}{*}{\multicolumn{2}{|c|}{ Total }} \\
\hline & \multicolumn{2}{|c|}{ Not on target } & \multicolumn{2}{|c|}{ On target } & & \\
\hline & $\mathrm{n}$ & $\%$ & $\mathrm{n}$ & $\%$ & $\mathrm{n}$ & $\%$ \\
\hline Negative & 48 & 50 & 1 & 1 & 49 & 51 \\
\hline Positive & 19 & 19.8 & 28 & 29.2 & 47 & 49 \\
\hline Total & 67 & 69.8 & 29 & 30.2 & 96 & 100 \\
\hline
\end{tabular}

Spearman Rho Test Statistical Test $\mathrm{p}=0.000$ and $\mathrm{r}=0.626$

Table 5 Cross Tabulation Of The Relationship Between Diet And Blood Pressure In Hypertensive Patients At Pandanwangi Health Center, Malang City

\begin{tabular}{|c|c|c|c|c|c|c|}
\hline \multirow{3}{*}{ Diet } & \multicolumn{4}{|c|}{ Blood pressure } & \multirow{2}{*}{\multicolumn{2}{|c|}{ Total }} \\
\hline & \multicolumn{2}{|c|}{ Not on target } & \multicolumn{2}{|c|}{ On target } & & \\
\hline & $\mathrm{n}$ & $\%$ & $\mathrm{n}$ & $\%$ & $\mathrm{n}$ & $\%$ \\
\hline Negative & 49 & 51 & 2 & 2.1 & 51 & 53.1 \\
\hline Positive & 18 & 18.8 & 27 & 28.1 & 45 & 46.9 \\
\hline Total & 67 & 69.8 & 29 & 30.2 & 96 & 100 \\
\hline
\end{tabular}

Spearman Rho Test Statistical Test $\mathrm{p}=0.000$ and $\mathrm{r}=0.609$

patients with hypertension at Pandanwangi Health Center, Malang City.

Table 5 shows that the majority of respondents have a negative diet with blood pressure that is not according to the target, namely as many as 49 respondents $(51 \%)$. Based on the results of the analysis using the Spearman Rank Test Correlation statistical test, it was found that the value of $p=0.000$ and $r=0.609$. $P$ value $<0.05(p=0.000)$ means $\mathrm{H} 1$ is accepted and indicates a relationship between diet and blood pressure in hypertensive patients at Pandanwangi Health Center, Malang City. The correlation coefficient value is positive $(r=0.609)$, which means that the strength of the relationship between diet and blood pressure is strong and unidirectional. The existence of a strong and unidirectional relationship shows that the better the level of diet, the better blood pressure in patients with hypertension at Pandanwangi Health Center Malang City.

Table 6 shows that as many as 54 respondents $(56.3 \%)$ have negative category physical activity with blood pressure that is not on target. Based on the results of the analysis using the Spearman Rank Test Correlation statistical test, the value of $\mathrm{p}=0.000$ and $r=0.449$ was obtained. $P$ value $<0.05(p=0.000)$ means $\mathrm{H} 1$ is accepted and indicates a relationship between physical activity and blood pressure in hypertensive patients at Pandanwangi Health Center, Malang City. The value of the correlation coefficient is positive $(r=0.449)$ which means that the strength of the relationship between physical activity and blood pressure is sufficient and unidirectional. The existence of a sufficient and unidirectional relationship indicates that the higher the level of physical activity, the better blood pressure in patients 
Table 6 Cross Tabulation Between Physical Activity And Blood Pressure In Hypertensive Patients At Pandanwangi Health Center, Malang City

\begin{tabular}{|c|c|c|c|c|c|c|}
\hline \multirow{3}{*}{ Physical Activity } & \multicolumn{4}{|c|}{ Blood pressure } & \multirow{2}{*}{\multicolumn{2}{|c|}{ Total }} \\
\hline & \multicolumn{2}{|c|}{ Not on target } & \multicolumn{2}{|c|}{ On target } & & \\
\hline & $\mathrm{n}$ & $\%$ & $\mathrm{n}$ & $\%$ & $\mathrm{n}$ & $\%$ \\
\hline Negative & 54 & 56.3 & 10 & 10.4 & 64 & 66.7 \\
\hline Positive & 13 & 13.5 & 19 & 19.8 & 32 & 33.3 \\
\hline Total & 67 & 69.8 & 29 & 30.2 & 96 & 100 \\
\hline & Spec & Test $S$ & lTe & and & & \\
\hline
\end{tabular}

Table 7 Cross Tabulation Of The Relationship Between Family Support And Blood Pressure In Hypertensive Patients At Pandanwangi Health Center, Malang City

\begin{tabular}{|c|c|c|c|c|c|c|}
\hline \multirow{3}{*}{ Family support } & \multicolumn{4}{|c|}{ Blood pressure } & \multirow{2}{*}{\multicolumn{2}{|c|}{ Total }} \\
\hline & \multicolumn{2}{|c|}{ Not on target } & \multicolumn{2}{|c|}{ On target } & & \\
\hline & $\mathrm{n}$ & $\%$ & $\mathrm{n}$ & $\%$ & $\mathrm{n}$ & $\%$ \\
\hline Less & 44 & 45.8 & 2 & 2.1 & 46 & 47.9 \\
\hline Enough & 22 & 22.9 & 17 & 17.7 & 39 & 40.6 \\
\hline Good & 1 & 1 & 10 & 10.4 & 11 & 11.5 \\
\hline Total & 67 & 69.2 & 29 & 30.2 & 96 & 100 \\
\hline
\end{tabular}

Spearman Rho Test Statistical Test $\mathrm{p}=0.000$ and $\mathrm{r}=0.607$

Table 8 Cross Tabulation Of The Relationship Between Medication Adherence And Blood Pressure In Hypertensive Patients At Pandanwangi Health Center, Malang City

\begin{tabular}{|c|c|c|c|c|c|c|}
\hline \multirow{3}{*}{$\begin{array}{l}\text { Compliance with } \\
\text { Medication }\end{array}$} & \multicolumn{4}{|c|}{ Blood pressure } & \multirow{2}{*}{\multicolumn{2}{|c|}{ Total }} \\
\hline & \multicolumn{2}{|c|}{ Not on target } & \multicolumn{2}{|c|}{ On target } & & \\
\hline & $\mathrm{n}$ & $\%$ & $\mathrm{n}$ & $\%$ & $\mathrm{n}$ & $\%$ \\
\hline Low & 51 & 53.1 & 1 & 1 & 52 & 54.2 \\
\hline Moderate & 12 & 12.5 & 9 & 9.4 & 21 & 21.9 \\
\hline High & 4 & 4,2 & 19 & 19.8 & 23 & 24 \\
\hline Total & 67 & 69.8 & 29 & 30.2 & 96 & 100 \\
\hline \multicolumn{7}{|c|}{ Spearman Rho Test Statistical Test $\mathrm{p}=0.000$ and $\mathrm{r}=0.726$} \\
\hline
\end{tabular}

with hypertension at Pandanwangi City Health Center Poor.

Table 7 shows that as many as 44 respondents (45.8\%) had less family support with blood pressure that was not on target. Based on the results of the analysis using the Spearman Rank Test Correlation statistical test, it was found that the value of $p=0.000$ and $r=0.607$. The $p$ value $<0.05(p=0.000)$ means that $\mathrm{H} 1$ is accepted and indicates a relationship between family support and blood pressure in hypertensive patients at Pandanwangi Health Center, Malang City. The correlation coefficient value is positive ( $r=0.607)$, which means that the strength of the relationship between family support and blood pressure is strong and unidirectional. The existence of a strong and unidirectional relationship shows that the better the level of family support, the better blood pressure in patients with hypertension at Pandanwangi City Health Center Poor.
Table 8 shows that as many as 51 respondents (53.1\%) had low medication adherence with nontarget blood pressure. Based on the results of the analysis using the Spearman Rank Test Correlation statistical test, it was found that the value of $p=0.000$ and $r=0.726$. $P$ value $<0.05(p=0.000)$ means $H 1$ is accepted and indicates a relationship between medication adherence and blood pressure in hypertensive patients at Pandanwangi Health Center, Malang City. The correlation coefficient value is positive $(r=0.726)$, which means that the strength of the relationship between medication adherence and blood pressure is strong and unidirectional. The existence of a strong and unidirectional relationship indicates that the better the level of diet, the better blood pressure in patients with hypertension at Pandanwangi City Health Center Poor. 


\section{DISCUSSION}

Diabetes Based on the results of research conducted from May to June 2020, it is known that the majority of respondents are female and aged 56-65 years (late elderly). The majority of the respondents' last education was high school level or equivalent (Senior High School / equivalent) and did not have a smoking habit, and the majority of respondents consumed Amlodipine type drugs. Based on the results of this study, it is known that there is a significant and unidirectional relationship between knowledge, attitudes, diet, physical activity, family support and adherence to taking medication with blood pressure.

\section{The Relationship between Knowledge and Blood Pressure in Pandanwangi Health Center, Malang City}

The results showed that the knowledge about controlling hypertension was related to blood pressure, where the higher the level of knowledge, the better the blood pressure of the respondents. This can be seen from the distribution of the frequency of knowledge and blood pressure of respondents where the majority of respondents still have less knowledge and blood pressure is not well controlled. The majority of respondents still do not know and understand about controlling high blood pressure, respondents are wrong in answering questions about how to control high blood pressure. Respondents know better how to treat hypertension, such as if there is a complaint, the respondent has to check blood pressure and take medication.

This is in line with the research conducted by Riri (2017) entitled "Factors related to Blood Pressure Control in Hypertension Patients at Puskesmas Harapan Raya Pekanbaru in 2016" states that knowledge has a major influence on controlling blood pressure in patients with hypertension. Knowledge is also closely related to the education level of the respondent. Mara, et al (2019), in their research stated that there was a significant relationship between the level of education and the knowledge level of hypertensive patients, where the higher the level of education, the better the respondent's knowledge.

Notoatmodjo (2014) states that knowledge about health includes what a person knows about ways to maintain health, including; knowledge of communicable and non-communicable diseases, knowledge of factors affecting health, knowledge of professional and traditional health service facilities, and others. Ragot et al (2005) stated that patient knowledge and awareness about blood pressure plays an important role in the ability to achieve successful blood pressure control in hypertension.(Wulansari, Ichsan, \& Usdiana, 2013). For that it is necessary to make efforts to improve health education regarding hypertension from its causes, symptoms, prevention, treatment, and complications. Efforts that can be made by personnel include providing psychoeducation and / or education to hypertension sufferers and their families so that respondents' knowledge increases.

\section{The Relationship Between Attitude and Blood Pressure in Pandanwangi Health Center, Malang City}

The results showed that the attitude of controlling hypertension was related to blood pressure, where the better the attitude, the more controlled the blood pressure was. The majority of respondents still have a negative attitude in controlling blood pressure. The results of the distribution of the questionnaire showed that the majority of respondents answered disagree and agreed on the points of regularly taking anti-hypertensive drugs, routine blood pressure checks to the nearest health service, and the diet they were taking. The majority of respondents answered strongly disagreeing to disagree on the points of exercise that should be done every day and habits of rest and relaxation without thinking about problems. 
Dian C's research (2010) states that there is a relationship between attitudes about hypertension and average blood pressure. And from the results of these studies it is concluded that the more positive a person's attitude about hypertension, the greater the awareness of controlling blood pressure. This is in line with research conducted by Riri (2017) entitled "Factors related to Blood Pressure Control in Hypertension Patients at Puskesmas Harapan Raya Pekanbaru in 2016" states that there is a relationship between respondents' attitudes and blood pressure control behavior.

Notoatmodjo (2007) states that a person's health is determined by the person's intention or attitude towards health services (behavior intention), social support from the community, whether or not there is information about health and health facilities. Green stated that a person's health behavior or level of health is determined by one's attitude towards health objects(Dirhan, 2012). In determining attitude, knowledge has an important role. Azwar (2012) states that there are 3 components in attitude, one of which is cognitive or knowledge. Yayuk (2004) states that a person's level of knowledge affects their attitude. More and more information can affect or increase someone's knowledge and with this knowledge it raises awareness that eventually someone will behave or behave in accordance with the knowledge obtained from experience, learning, or instructions.(Masyudi, 2018).

The results of this study indicate that the majority of respondents have a negative attitude in controlling blood pressure, so that blood pressure is not within the normal or controlled range. This is closely related to the knowledge possessed by respondents. The majority of respondents do not know how to control blood pressure properly, one of which is by routinely controlling blood pressure at least once a month, so that hypertensive sufferers do not control and think hypertension is a natural thing and respondents are not too worried about their health conditions. In addition, there are still many respondents who ignore or even reduce foods that are high in salt content, this is because the respondents' knowledge and belief about the disease is still low. In the opinion of researchers, attitudes are influenced by the respondent's knowledge, the better the respondent's knowledge in controlling hypertension, the more positive the attitude of hypertension sufferers in controlling their blood pressure. So that blood pressure can be controlled properly.

\section{The Relationship between Diet and Blood Pressure in Pandanwangi Health Center, Malang City}

The results showed that diet was related to blood pressure, where the better the diet done by hypertension sufferers in controlling hypertension, the better blood pressure. From the frequency distribution of the diet, it was found that the majority of respondents had negative dietary behavior and blood pressure was not on target, namely as many as 49 people. The majority of respondents still have not implemented the password that must be done. The results of the questionnaire distribution found that the majority of respondents still did not carry out instructions or directions from health workers regarding diet, often ate fatty meat, shellfish and crab, had not carried out a low cholesterol diet, did not limit the consumption of salt or foods containing salt, and did not consume cucumber which can lower blood pressure. Respondents are still wrong in their diet and do not reduce the amount of salt they consume every day. Respondents also found it difficult to avoid foods containing oil and coconut milk. This is because these foods have become a habit, making it difficult to avoid. Respondents prefer to take hypertension medication rather than avoid foods that trigger high blood pressure. Respondents with a negative diet category tend to have uncontrolled blood pressure. Conversely, respondents with a positive diet category tended to have normal or controlled blood pressure. 


\section{R. WARDANI ET AL.}

Respondents prefer to take hypertension medication rather than avoid foods that trigger high blood pressure. Respondents with a negative diet category tend to have uncontrolled blood pressure. Conversely, respondents with a positive diet category tended to have normal or controlled blood pressure. Respondents prefer to take hypertension medication rather than avoid foods that trigger high blood pressure. Respondents with a negative diet category tend to have uncontrolled blood pressure. Conversely, respondents with a positive diet category tended to have normal or controlled blood pressure.

Herawati, et al (2013) in their research entitled "Controlled Blood Pressure of Hypertension Patients based on Diet Patterns and Exercise Habits in Padang" states that some hypertensive sufferers still often eat meat, unhealthy lifestyles, obesity, lack of exercise, excessive salt consumption, and less fiber intake. So that there is a relationship between dietary patterns and controlling blood pressure in hypertensive patients. This is in line with research conducted by Riri (2017) entitled "Factors related to Blood Pressure Control in Hypertension Patients at Puskesmas Harapan Raya Pekanbaru in 2016" states that there is a relationship between the diet of hypertensive patients with blood pressure control behavior.

Food is one of the factors that triggers the emergence of hypertension, therefore it is necessary to adjust the food menu. The food regulation in question is applying a low-salt diet followed by a cholesterol and fat diet, then a high-fiber diet and a low-energy diet (Ridwan, 2013). The goal of a hypertensive diet is to reduce salt intake, increase fiber, stop bad habits, increase potassium intake, and meet magnesium needs. In addition, the aim of the hypertension diet is to help eliminate salt or water retention in the body and reduce blood pressure for people with hypertension. The diet carried out by the respondents is very influential on the health condition of people with hypertension, namely blood pressure. People who suffer from hypertension or are at risk of developing hypertension should take precautions as early as possible, one of which is by adjusting their diet properly. If people with hypertension consume more sodium and don't eat fibrous foods and don't avoid fatty foods, it will be difficult to control blood pressure itself.

\section{The Relationship between Physical Activity and} Blood Pressure at Pandanwangi Health Center, Malang City

The results showed that the physical activity of controlling hypertension was related to blood pressure, where the better the physical activity of the respondents, the more controlled the blood pressure would be. The results of the distribution of the questionnaire showed that the majority of respondents answered no to the points of habitual sports activities every day, doing sports activities $>30$ minutes a day. Respondents did not do sports regularly due to the inability of the respondents due to increasing age and complaints such as gout, rheumatism, and others. The respondents' spare time is mostly used for leisure, such as watching television or playing gadgets.

Hasanudinet al (2018) in his research stated that the lack of physical activity in respondents has an impact on increasing blood pressure. This is in line with Riri's research (2017) which states that there is a relationship between exercise and blood pressure control behavior, where respondents do not exercise regularly because of comorbidities. Herawa, et al (2013) in their research entitled "Controlled Blood Pressure of Hypertension Patients Based on Diet Patterns and Exercise Habits in Padang" showed that some respondents did not exercise regularly, so that blood pressure was not controlled.

Giam (2020) says regular physical activity helps increase the overall efficiency of the heart. Physically active individuals generally have lower blood pressure and are less likely to develop hypertension. 
Activities in the form of movement or aerobic exercise are useful for increasing and maintaining fitness and cardio-respirator endurance. Examples of aerobic exercises are walking, jogging, swimming and cycling(Hasanudin, Ardiyani, \& Perwiraningtyas, 2018). The results of a study conducted by Sihombing Marice (2017) show that a sufficient level of physical activity has a significant relationship with hypertension. Low physical activity has a risk of 1.61 times triggering the development of hypertension compared to high physical activity (Mahiroh, Astutik, \& Pratama, 2019).

Based on this study, it was found that the majority of respondents had a negative physical activity pattern so that blood pressure was out of control. This is because the majority of respondents are late elderly (56-65 years), so that their ability to move is decreasing. Respondents also said that they tire easily during activities and there are complaints such as rheumatism or stiff pains. With less physical activity, blood pressure is getting out of control. Efforts that can be made by respondents include getting used to small sports such as walking regularly, because the increased leg muscle strength when walking can increase the supply of oxygen to the heart and brain. Regular exercise will build muscle fitness, make it stronger, and of good quality in the amount of flexibility. For people with hypertension,

\section{Relationship between Family Support and Blood Pressure at Pandanwangi Health Center, Malang City}

The results showed that family support in controlling hypertension was related to blood pressure, where the better the support of families with hypertension, the better the respondent's blood pressure. In this study all respondents lived with their families, but when the study was conducted, many respondents conducted regular examinations at the health center. independently or unaccompanied by family members. The results of the distribution of the questionnaire showed that the majority of respondents answered never until sometimes in getting emotional support and appreciation and information support from family members, the majority of respondents answered sometimes to often instrumental support from family members.

Family support is essential for patients in controlling hypertension. Ambarwari (2010) in Rizkiyanti (2014) states that family support can strengthen each individual, create family strength, increase self-respect, has the potential as the main prevention strategy for all families in facing the challenges of daily life. Family duties in the health sector is the ability to recognize health problems, the ability to make decisions to overcome health problems, the ability to care for family members who are sick, the ability to modify the environment for the family to stay healthy and optimal, and the ability to take advantage of the health facilities available in their environment.(Wahyudi \& Arjun, 2020).

Based on this research, there are still many respondents who do not get full support from their families. This lack of family support results in uncontrolled blood pressure of hypertensive sufferers. House and Kahm (1985) in Friedman et al., (2010) states that there are four types of family support, including emotional support, appreciation support, information support, and instrumental support. Family support is an important factor for someone when someone has health problems and as a preventive strategy to reduce stress where the outlook on life will be broader and not easily stressed. Family support also plays a role in reducing anxiety, increasing enthusiasm for life, and commitment to undergo hypertension treatment so as to achieve the goal of hypertension treatment, namely controlling blood pressure. This is in line with the research conducted by Herlina et al. (2011) entitled "The Relationship between Family Support and Elderly Behavior in Controlling Hypertension", it was found that family emotional support affects a person's 


\section{R. WARDANI ET AL}

feelings and motivation, there is also a relationship between information support and elderly behavior. hypertension which is physiologically forgetful and slow in receiving stimuli.

Family support is urgently needed by people with hypertension for a long time and continuously in controlling blood pressure so that controlled blood pressure can be realized in people with hypertension. Family members must work together so that people with hypertension have blood pressure within normal limits, this support can be in the form of emotional support, appreciation, instrumental and information. Some of the efforts that can be made by family members include emotional support such as assisting hypertension sufferers in treatment; instrumental support such as providing time and facilities for hypertensive sufferers in treatment; and information support such as by reminding about foods that are prohibited for consumption, providing information about hypertension,

\section{The Relationship between Medication Adherence and Blood Pressure at Pandanwangi Health Center, Malang City}

The results showed that medication intake was related to blood pressure, where the higher the level of adherence to taking medication, the better the blood pressure of people with hypertension. The majority of respondents with low medication adherence have barriers to drug consumption. The results of the distribution of the questionnaire showed that the majority of respondents answered yes to the point that sometimes they forget not to take medicine and bring medicine when traveling, deliberately not taking medication in the last 2 weeks, and stop taking antihypertensive drugs when they feel healthy. respondent's age often forgets to take the antihypertensive drug.

Dewanti, et al (2015) stated that patient adherence in taking medication is defined as the level of patients following the given treatment recommendations. According to Suparyanto (2010), the level of individual medication adherence is influenced by several factors, including knowledge, age, education, accommodation, changes in therapy models, modification of environmental and social factors, and family support. In this study, the majority of respondents who had a low level of adherence to taking medication were late elderly with their last education from junior high to high school. Respondents still do not have awareness about the importance of taking medication regularly and regularly, because more respondents take medication only when they are reminded or when they feel a complaint. Respondents also tended not to carry out routine checks to health services because the distance between the house and the health facilities was too far and the queuing time waiting for services was long. This is in line with the research conducted by Anwar and Rusni in 2019 entitled "The Relationship of Adherence to Taking Antihypertensive Medication with Blood Pressure in Elderly Patients with Hypertension in the Working Area of Puskesmas Air Putih Samarinda", stating that there is a relationship between adherence to taking antihypertensive drugs and blood pressure. in elderly people with hypertension. Hairunisa's research (2014) also shows that there is a relationship between medication adherence and controlled blood pressure in people with hypertension. This is in line with the research conducted by Anwar and Rusni in 2019 entitled "The Relationship of Adherence to Taking Antihypertensive Medication with Blood Pressure in Elderly Patients with Hypertension in the Work Area of Puskesmas Air Putih Samarinda", stating that there is a relationship between adherence to taking antihypertensive drugs and blood pressure. in elderly people with hypertension. Hairunisa's research (2014) also shows that there is a relationship between medication adherence and controlled blood pressure in people with hypertension. This is in line with the research conducted by Anwar and Rusni in 
2019 entitled "The Relationship of Adherence to Taking Antihypertensive Medication with Blood Pressure in Elderly Patients with Hypertension in the Work Area of Puskesmas Air Putih Samarinda", stating that there is a relationship between adherence to taking antihypertensive drugs and blood pressure. in elderly people with hypertension. Hairunisa's research (2014) also shows that there is a relationship between medication adherence and controlled blood pressure in people with hypertension. states that there is a relationship between adherence to taking antihypertensive drugs with blood pressure in elderly people with hypertension. Hairunisa's research (2014) also shows that there is a relationship between medication adherence and controlled blood pressure in people with hypertension. states that there is a relationship between adherence to taking antihypertensive drugs with blood pressure in elderly people with hypertension. Hairunisa's research (2014) also shows that there is a relationship between medication adherence and controlled blood pressure in people with hypertension.

Adherence to taking medication greatly affects a person in controlling blood pressure. The more obedient a person is in taking antihypertensive drugs, the more controlled blood pressure will be within normal limits. The success of a therapy is not only determined by the diagnosis and selection of the right type of drug but also by the compliance of hypertensive patients in carrying out antihypertensive drug therapy. One indicator of adherence to taking antihypertensive drugs is controlled blood pressure. Adherence to taking medication can be increased by the efforts that can be made by health workers, families, and people with hypertension. The role of health workers is very important to provide education to people with hypertension and their families about the importance of taking antihypertensive drugs regularly so that controlled blood pressure can be achieved. Families can play an active role in adherence to taking medication for hypertension sufferers by reminding and preparing drugs that must be taken by people with hypertension.

\section{CONCLUSION}

Knowledge of hypertension control related to blood pressure in hypertensive patients at Pandanwangi Health Center, Malang City. A strong and unidirectional relationship between knowledge and blood pressure in patients with hypertension shows that the better the level of knowledge in controlling hypertension, the more controlled blood pressure in patients with hypertension. The attitude of controlling hypertension is related to blood pressure in hypertensive patients at Pandanwangi Health Center, Malang City. A strong and unidirectional relationship between attitudes and blood pressure of hypertensive patients in controlling blood pressure shows that the more positive the patient's attitude in controlling hypertension, the more controlled the blood pressure of hypertension sufferers. Diet is related to blood pressure in hypertensive patients at Pandanwangi Health Center, Malang City. The existence of this relationship shows that the better the diet carried out by hypertensive sufferers, the more controlled blood pressure of patients with hypertension. Physical activity is related to blood pressure in people with hiotension at Pandanwangi Health Center, Malang City. A sufficient and unidirectional relationship between physical activity and blood pressure shows that the more positive the physical activity is carried out, the more controlled the blood pressure of patients with hypertension. Family support is related to the blood pressure of hypertension sufferers at Pandanwangi Health Center, Malang City. This strong and unidirectional relationship between family support and blood 


\section{R. WARDANI ET AL.}

pressure shows that the better family support is given, the more controlled blood pressure is in people with hypertension. Compliance with taking medication is related to blood pressure in hypertensive patients at Pandanwangi Health Center, Malang City. The existence of a strong and unidirectional relationship between adherence to taking medication with blood pressure indicates that the higher the level of adherence to taking antihypertensive drugs, the more controlled the blood pressure of patients with hypertension

\section{REFERRENCE}

Artiyaningrum, B. (2011). Factors related to the incidence of uncontrolled hypertension in patients undergoing routine examinations at the Kedungmundu Public Health Center, Semarang City in 2014. Semarang State University.

Datin, I. (2014). Heart Health Situation. Center for Data and Information of the Indonesian Ministry of Health. Jakarta.

Dirhan, D. (2012). Relationship of Knowledge, Attitude and Obedience to Treatment with Degrees of Systole and Diastole in Hypertension Patients at Sukamerindu Public Health Center, Bengkulu City. Pharmaceutical Scientific Journal, 9 (1).

Hasanudin, H., Ardiyani, VM, \& Perwiraningtyas, P. (2018). The relationship between physical activity and blood pressure in people with hypertension in the Tlogosuryo area, Tlogomas Village, Lowokwaru District, Malang City. Nursing News: Scientific Journal of Nursing, 3 (1).

Maharani, R., \& Syafrandi, DP (2017). Factors Associated with Blood Pressure Control Behavior in Patients with Hypertension at Puskesmas Harapan Raya, Pekanbaru City in 2016. Journal of Community Health, 3 (5), 165-171.

Masyudi, M. (2018). Factors related to the behavior of the elderly in controlling hypertension. AcTion: Aceh Nutrition Journal, 3 (1), 57-64.
Wahyudi, WT, \& Arjun, F. (2020). Relationship of Family Support in Patients with High Blood Pressure in Controlling Hypertension in the Work Area of the Panjang Health Center, Bandar Lampung City. Malahayati Nursing Journal, 2 (3), 525-534. 